\title{
A short biography of Mats Hillert
}

Mats Hillert was born in Gothenburg, Sweden on 28th of November 1924. He was the youngest of the three sons of Anna and Hildding Hillert. As they were very lively the young Hillert brothers were well known in the local neighbourhood.

Mats grow up in Gothenburg and went to high school at Realläroverket, later named Vasa Läroverk. He earned his B.S. in chemical engineering at Chalmers Technical University in Gothenburg in 1947 with a bachelor's thesis on diffusion of radioactive $\mathrm{Ag}$ in $\mathrm{Ag}_{2} \mathrm{HgJ}_{4}$ under the supervision of Karl Erik Zimen, a former student of Carl Wagner whose oxidation theory connected electrical conductivity with diffusion.

After his military service Mats started his research career as a scientist at the Swedish Institute for Metals Research in 1948. Mats was assigned to look into the use of internal friction but was left with a high degree of freedom. On the side he could thus start to work on the use of radioactive isotopes to study the distribution of various elements in metals. He also contacted Gudmund Borelius, who was professor of physics at Royal Institute of Technology, KTH, wanting to register for graduate studies. He was told that he first had to take the undergraduate courses for physicists that were not included in the chemistry curriculum. For a few years he spent most of his spare time on those studies, which was possible because his girl friend still went to school in Gothenburg. At work Mats came in contact with Sten and Helfrid Modin, two Swedish metallographers and early pioneers in the use of electron microscopy to study the microstructure of steels. Sten Modin inspired Mats to add yet another undergraduate course at KTH and thus participated in the lectures of Axel Hultgren who was professor in physical metallurgy at the nearby KTH. Mats says that his life-long deep interest in phase transformations and thermodynamics started with a scientific argument after one of these lectures. Mats felt that Hultgren's reasoning on the effect of $\mathrm{Ni}$ on carburization of steel was thermodynamically incorrect and told Hultgren his opinion. Hultgren, the grand old man of Swedish physical metallurgy, became impressed of this young scientist who showed such a remarkable intuition in thermodynamics and suggested that one should resolve the issue by an experiment. Of course the experiment showed that Mats was correct and it eventually led to a joint publication of Hultgren and Hillert in 1953. At that time Hultgren had developed the concept of paraequilibrium, which also concerned the effect of alloying elements on transformations in steel. This contact with Hultgren resulted in a number of manuscripts centred around the concept of paraequilibrium and isoactivity lines in phase diagrams and their applications to transformations in steels. Mats assignment on internal friction was simply forgotten by that time.

Eric Rudberg, who was the director of the Swedish Institute for Metals Research, encouraged Mats to apply for a grant from the Sweden-America Foundation. With his wife since 1951, Gerd, he thus moved to Boston and MIT in 1953 and started his studies under the supervision of the legendary teacher Morris Cohen. At MIT he also met Carl Wagner who taught thermodynamics and gave Mats valuable advice on some of his manuscript, which had all been rejected. He was then able to publish some, some were published later but one was not published until the present volume. His topic for the Master's thesis was an experimental study of the thermodynamics of the Ag-Al system. Inspired by one of his fellow students, Larry Kaufman, who was modelling the thermodynamic properties of the Fe-Ni system, Mats applied a similar model to the $\mathrm{Ag}-\mathrm{Al}$ system and that work was the starting point for his life-long interest in the thermodynamics of alloys. Mainly by the efforts of Kaufman, that procedure has since developed into what is now called CALPHAD. From another fellow student, Eric Kula, he learned about the effect of fine inclusions on grain growth, which inspired him to start developing a mathematical theory for grain growth. After a Master's degree Mats was invited to stay for the Doctorate and while spending a semester to prepare for the qualifying exam he could not help worrying about the strange behaviour of Au-Ni alloys that one of his room mates, Ervin Underwood, was studying. He connected it with the phenomenon later called spinodal decomposition, which was the main research interest of Borelius at KTH. It lead him to developing a theory for that phenomenon. Fortunately, 
this topic fitted into one of Cohen's research programs and Mats could finish his degree after adding an experimental study of spinodal decomposition. He left MIT with a Doctor of Science in 1956 and returned to the Swedish Institute of Metal Research in Stockholm. A coincidence deserves mention. Another of Mats' room mates was John Hilliard who brought a copy of his thesis with him when he left for GE in Schenectady in 1956. There he met John Cahn and together they completed the theory of spinodal decomposition and thus opened up a new field.

During the Mats' stay in the US professor Hultgren had retired and Curt Amberg, a well known industrial researcher and an expert in heat treating, had been appointed as the new professor in physical metallurgy. However, he became seriously ill and passed away 1959. Mats was then appointed as a temporary replacement and started teaching in physical metallurgy. The coming years he published a large number of papers, some of them ground breaking, and when the position as professor in physical metallurgy was announced, Mats applied and was appointed full professor 1961. He remained at that position until his retirement 30 years later.

As a professor Mats taught several generations of Swedish metallurgists the most up to date knowledge in the fundamentals of physical metallurgy. He launched the graduate teaching on the subject and acted as the main supervisor of more than 30 doctors which are now active in Swedish industry or academia worldwide.

Mats Hillert is a fellow of the Royal Swedish Academy of Engineering Sciences and the Royal Swedish Academy of Sciences. He is also a fellow of ASM International and a Fellow of Met. Soc. AIME (TMS). His list of awards is impressive and includes, to mention only a few, R.F. Mehl medalist (Met. Soc. AIME), Bakhuis Roozeboom Gold Medal (Royal Acad. Netherland), Acta Metallurgica Gold Medal, Murakami Gold Medal (Japan Inst. Metals, Japan), Björkén award (Uppsala University, Sweden), Hume-Rothery Award (TMS, USA) .

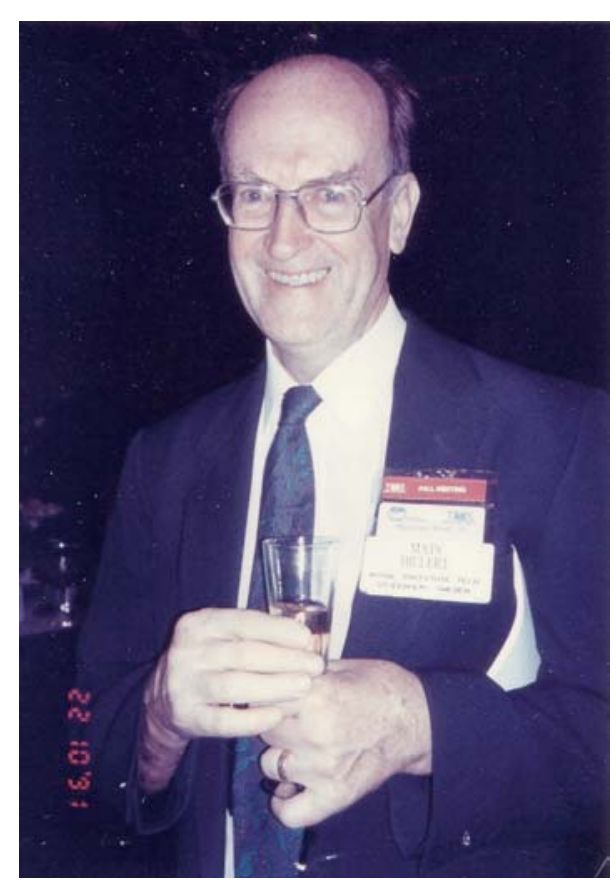

Mats Hillert at the TMS fall meeting in 1991. 